\title{
Development and Application of Ancient Timber Buildings Structural Condition Assessment Model Based on a Fuzzy Matter-Element Model that Includes Asymmetric Proximity
}

\author{
Zhongwei Gao $\mathbb{D}^{1,2}$ Donghui Ma, ${ }^{1,3}$ Wei Wang, ${ }^{1,3}$ Xiaodong Guo $\mathbb{D}^{1,3}$ and Qingzi Ge \\ ${ }^{1}$ Institute of Earthquake Resistance and Disaster Reduction, Beijing University of Technology, Beijing 100124, China \\ ${ }^{2}$ Sichuan Institute of Building Research, Chengdu 610081, China \\ ${ }^{3}$ Key Scientific Research Base of Safety Assessment and Disaster Mitigation for Traditional Timber Structure \\ (Beijing University of Technology), State Administration for Cultural Heritage, Beijing 100124, China
}

Correspondence should be addressed to Xiaodong Guo; gxd@bjut.edu.cn

Received 29 March 2018; Revised 17 August 2018; Accepted 27 August 2018; Published 24 September 2018

Academic Editor: Filippo Ubertini

Copyright (C) 2018 Zhongwei Gao et al. This is an open access article distributed under the Creative Commons Attribution License, which permits unrestricted use, distribution, and reproduction in any medium, provided the original work is properly cited.

\begin{abstract}
To properly protect ancient buildings, it is vitally important to determine the health status of these structures in a timely manner. To easily, quickly, reliably, and quantitatively assess the structure health of ancient timber buildings, this paper proposes a structure health assessment method based on fuzzy matter-element theory improved by asymmetric proximity, and the specific assessment steps are given. First, a fuzzy matter-element model is constructed; then, to effectively solve the failure problem of the maximum membership principle, the fuzzy matter-element assessment model is improved by using the theory of asymmetric proximity. The weights determined by the entropy weight and clustering methods are then combined through the game theory combination weighting concept and, finally, the structural condition of the ancient timber buildings is classified into five grades: I favorable, II ordinary, III poor, IV inferior, and V dangerous. Ten evaluation factors were chosen: bearing capacity of the foundation soil, subbase deformation, foundation damage, column and foundation connection, bearing capacity of members, connection construction, member deformation, crack slope, crack depth, and decayed/insect attacked. Taking a building built in the Republican Period in Sino-Ocean Taikoo Li, Chengdu, as an example, this model was used to assess the building's structural condition. The results show that this method is feasible to quantitatively assess the structural condition of ancient timber buildings. It is a simple and practical assessment method that can provide a decision-making basis for maintenance, protection, and reinforcement of ancient timber buildings.
\end{abstract}

\section{Introduction}

Ancient Chinese architecture mainly consists of timber structures [1], with nonrenewable, irreplaceable resource characteristics. Due to material aging, environmental erosion, defects, natural disasters, and various human factors, many ancient buildings are in bad condition and are in urgent need of effective protection [2].

In recent years, scholars at home and abroad have carried out many studies on ancient buildings and have achieved good results. In general, the safety assessment methods of ancient timber buildings are mainly classified into experimental type $[3,4]$, numerical simulation type $[5,6]$, summary and analysis type $[7,8]$, detection type $[9,10]$, and monitoring type [11, 12].
Experimental type: Zhang et al. [13] used a shaking table test to study the seismic behavior of Chinese ancient timber buildings. Xue et al. [14] studied the seismic energy dissipation of ancient timber buildings by using a shaking table and then proposed the earthquake damage assessment model of energy dissipation for members/structures. Yang et al. [15] conducted an experimental study on the mechanical properties of the timber in ancient Tibetan buildings. This type of method has the advantages of intuitiveness and minimal errors in experimental results, but it also has the disadvantages of complicated operation, high cost, the fact that only data for a specific area can be obtained, etc.

Numerical simulation type: Jaishi et al. [5] calculated the period of natural vibration of Nepali temple by means of 
numerical simulation (finite element method) and instrumental tests (environmental excitation) and evaluated the seismic capacity of the temple by using a seismic coefficient method. Tan et al. [16] analyzed the column-foot sliding phenomenon of ancient buildings under earthquake conditions and evaluated the effect of column-foot sliding on the seismic performance of ancient timber buildings. This type of method has the advantages of obtaining the simulated results of each area and each point quickly, as well as being less costly. However, its boundary conditions and material properties need to be simplified; it may have impact on the analysis results more or less. Besides, the results and accuracies may be different and with high randomness because the results are discretized in different forms.

Summary and analysis type: Zhou et al. [8] studied the typical aseismic problems existing in Chinese ancient timber buildings that include decay of column root, slack of TouKung, tenon pulled out of mortise, cracks of beam and column, and so on, analyzed the causes of these problems, and proposed corresponding reinforcement methods. In order to protect historic buildings from fire, Naziris et al. [17] proposed a selection and resource allocation model. This type of method is simple and practicable and can make full use of the existing research results as well as can pool ideas. However, it requires mastery of a lot of data, and it relies heavily on the availability of historical data.

Detection type: Pesci et al. [9] adopted laser scanning technology to detect and analyze the deformation of the Asinelli tower and Garisenda tower in Bologna, Italy. The results show that the tower is very sensitive to dynamic loads and should avoid or reduce the loads caused by human factors (such as the vibration caused by vehicle traffic). Xue et al. [18] studied the effect of vibration characteristics produced by subway trains on ancient timber buildings. Calderón et al. [19] studied the effect of environmental (temperature and humidity) changes on the dynamic properties of ancient masonry buildings. This type of method has the advantages of being quick, efficient, convenient, labor saving, and so on. However, detecting personnel requires advanced professional knowledge and detection skills.

Monitoring type: Fregonese et al. [20] introduced the Terrestrial Laser Scanner, which is mainly used in the monitoring of large structures into ancient buildings; this technology can build a very realistic 3D model. Dai et al. [21] collected data on material stress and deformation of structural members through the monitoring systems to study the relationship between temperature changes and strain increments. This type of method has the advantages of high sensitivity and real-time monitoring data can be provided. However, it is time-consuming and needs cautious handling by experienced professionals.

At present, there is still a lack of research on structural safety comprehensive assessment methods of ancient building. How to effectively synthesize the advantages of experimental type, numerical simulation type, summary and analysis type, detection type, and monitoring type and construct a more complete structural safety comprehensive assessment system of ancient building is a question worth discussing.
Common assessment methods include the grey incidence degree method [22], the projection pursuit regression method [23], the attribute recognition method [24], and the fuzzy comprehensive method [25]. The advantages of the abovementioned assessment models are that they are easy to operate and convenient to calculate, but there are still some scientific and practical shortcomings. One such shortcoming is that the number of model control variables is limited; they are not suitable for multiobjective decision-making and multiindex assessment, and the weight assignment of assessment indexes is not reasonable. Another shortcoming is that the assessment method is simple; that is, it mainly adopts a single model for lack of consideration for cooperation between different models, without comprehensive consideration of the weight and so on.

The essence of assessing the structural condition of ancient timber buildings is the nonlinear and nondeterministic problems of the main influencing factors. Therefore, the use of effective treatments is very important. In view of the fact that the traditional matter-element assessment model can easily lose part of the information, this paper uses the asymmetric proximity method to improve the traditional matterelement assessment model, calculates assessment weights by using the entropy method and the clustering weight method to form the comprehensive weight, and constructs a comprehensive assessment method based on a fuzzy matterelement model improved by asymmetric proximity. Finally, the scientificity of the assessment method constructed is verified by examples, hoping to provide new ideas and new methods for the assessment of the structural condition of ancient timber buildings.

\section{Method}

Matter-element analysis theory consists of matter-element theory and extension set theory, the former studies conditions, and how things change and explores the ways in which things transform, whereas the latter is a mathematical tool for matter-element analysis. According to the multiindex assessment model built based on matter-element theory, the quantitative assessment results can be given with higher credibility and modern computer technology can be fully utilized for programming and calculation, and the assessment results can be quickly concluded [29].

2.1. Fuzzy Matter-Element Assessment Model. The fuzzy matter element takes the ordered three-dimensional population of things, properties, and fuzzy values as the basic elements in describing things; this three-dimensional approach allows us to quantitatively calculate and qualitatively analyze the characteristics or indexes of things [30], as expressed in

$$
R=(N, C, V)
$$

where $N$ is the name of a given thing, $C$ is the feature name of the given thing, $V$ is the magnitude of $N$ about feature $C$, and $R$ is called the fuzzy matter element if $V$ has fuzzification.

A given thing $N$ has $n$ properties $\left(C_{1}, C_{2}, \ldots, C_{n}\right)$ and each property has $m$ evaluations $\left(v_{1}, v_{2}, \ldots, v_{m}\right)$; then $R$ is 
called the $n$-dimensional fuzzy matter element, and it can be expressed as follows:

$$
R_{\mathrm{nm}}=\left[\begin{array}{ccccc}
N_{1} & N_{2} & \cdots & N_{m} \\
c_{1} & u\left(x_{11}\right) & u\left(x_{12}\right) & \cdots & u\left(x_{1 m}\right) \\
c_{2} & u\left(x_{21}\right) & u\left(x_{22}\right) & \cdots & u\left(x_{1 m}\right) \\
\vdots & \vdots & \vdots & \ddots & \vdots \\
c_{n} & u\left(x_{n 1}\right) & u\left(x_{n 2}\right) & \cdots & u\left(x_{1 m}\right)
\end{array}\right]
$$

where $R_{\mathrm{nm}}$ is the $n$-dimensional fuzzy matter element of $m$ matter elements, $N_{j}$ is the $j_{t h}$ matter element $j=(1,2, \cdots$, $m), c_{i}$ is the $i_{\text {th }}$ characteristic of the $j_{\text {th }}$ matter element $N_{j}$, $X_{i j}(i=1,2, \ldots, n)$ is the magnitude of $c_{i}, u\left(x_{i j}\right)$ represents the fuzzy magnitude of $X_{i j}$, and the fuzzy magnitude is called membership.

When calculating, $u\left(x_{\mathrm{ij}}\right)$ can be standardized with the better fuzzy membership principle, that is, the smaller the superior model

$$
u_{i j}=\frac{X_{i j}}{\min X_{i j}}
$$

the bigger the superior model

$$
u_{i j}=\frac{X_{i j}}{\max X_{i j}}
$$

where $X_{i j}$ is the $i_{t h}$ characteristic magnitude of the $j_{t h}$ matter element and $\min X_{i j}$ and $\max X_{i j}$ are the minimum and maximum values of $X_{i j}$,respectively.

Membership function is obtained by a large amount of data observation and scientific calculation. The normal distribution function is generally used to represent the rules of distribution [30], that is,

$$
\mu(x)=\exp \left[-\left(\frac{x-k_{0}}{t}\right)^{2}\right]
$$

where $t$ is the parameter and $t>0, k_{0}$ is the mean of the corresponding grade of the parameter range, and $x$ is the fuzzy variable that represents characteristic magnitude.

Because the grade assessment criteria of the characteristic magnitude are mostly set as the parameter range, its boundary value is fuzzy, and it is a transition state of two grades. Therefore, it is feasible for the boundary value to belong to either of the two grades. From (5) we can see that when $x=$ $k_{0}, \mu(x)=1$ is the maximum value; that is, the memberships of the two grades are both equal to 0.5 , so there is

$$
\begin{gathered}
\mu(x)=\exp \left[-\left(\frac{x_{a}-x_{b}}{2 t}\right)^{2}\right] \approx 0.5 \Longrightarrow \\
\left\{\begin{array}{l}
t=\frac{x_{a}-x_{b}}{1.665} \\
k_{0}=\frac{x_{a}-x_{b}}{2}
\end{array}\right.
\end{gathered}
$$

where $x_{a}$ and $x_{b}$ are the upper and lower boundary values of the corresponding grade of the parameter range, respectively.
2.2. Fuzzy Matter-Element Assessment Model Improved by Asymmetric Proximity. The traditional matter-element assessment model commonly uses the principle of maximum membership to assess the calculation results. It is difficult for this principle to reflect the fuzzification of boundaries of the object to be assessed and easily loses partial information, which may lead to the failure of some assessment results. The literature [31] shows that it can effectively solve the maximum membership principle failure problem. This paper adopts the asymmetric proximity method instead of the maximum membership principle to calculate the degree of association and to assess the grade. The calculation steps of establishing the fuzzy matter-element assessment model with asymmetric proximity are as follows.

The first step is to construct the membership vector of the $i_{\text {th }}$ evaluation index:

$$
\begin{aligned}
\mathrm{B}= & \left(b_{1}, b_{2}, \ldots, b_{m}\right) \\
& =\left(W_{1}^{*} \sum_{i=1}^{n} u\left(x_{i 1}\right), W_{2}^{*} \sum_{i=1}^{n} u\left(x_{i 2}\right), \ldots, W_{n}^{*}\right. \\
& \left.\cdot \sum_{i=1}^{n} u\left(x_{i m}\right)\right)
\end{aligned}
$$

where $W_{i}^{*}$ is the comprehensive weight and $u(x)$ can be calculated by (5) and (6).

The second step is to normalize the membership vector $B_{i}$.

First, put $b_{i}$ at the end, for any $i_{1}, i_{2}\left(\in i_{m}\right) ;$ if $\left|i_{1}-i\right|>\left|i_{2}-i\right|$, then put $b_{i 1}$ in front of $b_{i 2}$; if $\left|i_{1}-i\right|=\left|i_{2}-i\right|$ and $i_{1}>i_{2}$, then put $b_{i 1}$ in front of $b_{i 2}$. The membership vector $B_{i}$ can be written as $B_{i}^{j}$ after normalization.

The third step is to construct the feature fuzzy subset $D_{j}$ :

$$
D_{j}=\left(d_{1}, d_{2}, \ldots, d_{m}\right)
$$

where $d_{i}$ is a member of the $j_{\text {th }}$ feature relative to the $i_{\text {th }}$ feature and if $j=i, d_{i}=1$; otherwise $d_{i}=0 ; i=1,2, \cdots, m$, $j=1,2, \cdots, n$.

The fourth step is to calculate the asymmetric proximity.

Asymmetric proximity $N(\boldsymbol{A}, \boldsymbol{B})$ between vectors $\boldsymbol{A}$ and $\boldsymbol{B}$ can be characterized as follows:

$$
N(\boldsymbol{A}, \boldsymbol{B})=1-\frac{1}{m} \sum_{k=1}^{m}\left|\mu_{\mathbf{A}}^{1 / P}\left(x_{k}\right)-\mu_{\mathbf{B}}^{1 / P}\left(x_{k}\right)\right|^{k}
$$

where $P$ plays a regulatory role in the calculation of results and can mutually compensate for the role of $k(k \epsilon j)$, so as to make the calculation results more conducive to grade. However, the value of $P$ should not be too big and should depend on the specific situation. Otherwise, when there are many objects to be assessed, the assessment results will congregate close to 1 or 0 , which is not conducive to grade; in general, $P=1[31]$.

Then the asymmetric proximity $N\left(\boldsymbol{B}_{i}^{j}, \boldsymbol{D}_{j}\right)$ between the membership $B_{i}^{j}$ and the objects features fuzzy subset $D_{j}$ can be obtained:

$$
N\left(\boldsymbol{B}_{i}^{j}, \boldsymbol{D}_{j}\right)=1-\frac{1}{m} \sum_{j=1}^{m}\left|B_{i}^{j}-D_{j}\right|^{j}
$$


The fifth step is to assess the results:

$$
\begin{aligned}
& R^{*}
\end{aligned}
$$

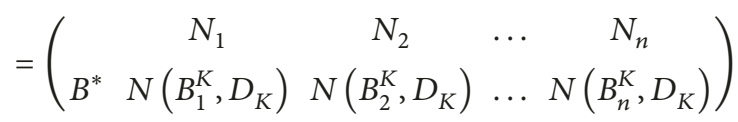

$$
\begin{aligned}
& N\left(\boldsymbol{B}_{i}^{k}, \boldsymbol{D}_{k}\right)=\max _{1 \leq j \leq m} N\left(\boldsymbol{B}_{i}^{j}, \boldsymbol{D}_{j}\right)
\end{aligned}
$$

where $N\left(\boldsymbol{B}_{i}^{k}, \boldsymbol{D}_{k}\right)$ represents the asymmetry proximity of this assessment object belonging to grade $v_{k}$ and $k$ represents $j$ when $N\left(\boldsymbol{B}_{i}^{j}, \boldsymbol{D}_{j}\right)$ takes the maximum value.

\section{Determination of Comprehensive Weight}

The credibility of the assessment conclusions depends directly on whether the weight of each index is scientific and reasonable. To minimize the incredibility of the conclusion due to each irrational and unscientific weight coefficient, the entropy weight method and clustering weight method are used to calculate the weight of each evaluation index, and the comprehensive weight is obtained from the combination of the weights mentioned above through the game theory combination weighting concept.

3.1. The Entropy Weight Method. Entropy reflects the dispersion degree of the research object and it is the best measurement of the uncertainty problems. The basic principle of the entropy method is to determine the weight of the evaluation factors by calculating the degree of variation of the characteristic value of the evaluation factors; that is, the greater the degree of variation of the characteristic value, the smaller the entropy and the greater the weight of the corresponding factors and vice versa. This method avoids human subjectivity and produces accurate results [32]. The main steps are as follows.

The first step is to construct the original decision-making matrix:

$$
R=\left(x_{i j}\right)_{n m} \quad(i=1,2, \ldots, n ; j=1,2, \ldots, m)
$$

The second step is to normalize the decision-making matrix.

In the assessment system, the quantization intervals and the order of magnitude of each index are different, and some are contradictory. For example, for some indexes, the higher the index value is, the better the result will be, but individual indexes may have opposite results. Thus, it is necessary to normalize each evaluation index. Equation (14) is used to normalize positive factors, whereas (15) is used to normalize negative factors.

$$
\begin{aligned}
& b_{i j}=\frac{x_{i j}-x_{\min }}{x_{\max }-x_{\min }} \\
& b_{i j}=\frac{x_{\max }-x_{i j}}{x_{\max }-x_{\min }}
\end{aligned}
$$

where $b_{i j}$ is the standard value after normalization, $x_{i j}$ is the standard value before normalization, and $x_{\min }$ and $x_{\max }$ are the minimum and maximum standard values of the parameter range, respectively.

The third step is to calculate the weight allocation of each index:

$$
P_{i j}=\frac{b_{i j}}{\sum_{i=1}^{m} b_{i j}} \quad(i=1,2, \ldots, n ; j=1,2, \ldots, m)
$$

where $P_{i j}$ is the weight allocation of one index.

The fourth step is to calculate the entropy value of each index:

$$
e_{i}=-K \sum_{i=1}^{n} P_{i j} \ln P_{i j} \quad(i=1,2, \ldots, n ; j=1,2, \ldots, m)
$$

where $K=1 / \ln (\mathrm{n})$ and if $P_{i j}=0$, then $P_{i j} \ln P_{i j}=0$.

The fifth step is to calculate the entropy weight value of each index:

$$
w_{i}=\frac{1-e_{i}}{\sum_{i=1}^{n}\left(1-e_{i}\right)} \quad(i=1,2, \ldots, n)
$$

where $\sum w_{i}=1$. Equation (18) shows that the larger the entropy value, the smaller the entropy weight and the smaller the contribution to the assessment result and vice versa.

3.2. The Clustering Weight Method. The clustering weight method includes (1) the simple threshold method, (2) the threshold specimen method, (3) the expert experience method, and (4) the specimen mean difference value method. The traditional clustering model usually uses the simple threshold method to calculate the clustering weight, but this method does not take into consideration the varied amplitudes of the standard values between different indexes. The weight of each evaluation index at different grades can be determined by using the revised cluster weight method, not only taking into account the measured values of the specimens but also involving the standard value of each grade of the evaluation index [33]. The main calculation steps are as follows.

The first step is to construct the original decision-making matrix:

$$
R=\left(x_{i j}\right)_{n m} \quad(i=1,2, \ldots, n ; j=1,2, \ldots, m)
$$

The second step is to normalize the data according to (14) and (15).

The third step is to calculate the weight allocation of each index:

$$
\begin{aligned}
& x_{i j}^{0}=\frac{x_{i j}}{\sum_{i=1}^{m} x_{i j}} \quad(i=1,2, \ldots, n ; j=1,2, \ldots, m) \\
& y_{i j}^{0}=\frac{x_{i j}^{\prime}}{x_{i j}^{0}} \quad(i=1,2, \ldots, n ; j=1,2, \ldots, m)
\end{aligned}
$$

where $y_{i j}^{0}$ is the weight allocation of each index and $x_{i j}^{\prime}$ is the value of the actual specimen after normalization. 
The fourth step is to calculate the clustering weight:

$$
Z_{i}=\frac{\sum_{j=1}^{m} y_{i j}^{0}}{\sum_{i=1}^{n} \sum_{j=1}^{m} y_{i j}^{0}}
$$

where $Z_{i}$ are the clustering weights of the $i_{t h}$ index.

3.3. Determine the Comprehensive Weight with the Game Theory Method. The model established determines each weight by using the information entropy and clustering methods and then uses game theory to obtain the comprehensive weight, that is, to find agreement or compromise between different weights and minimize the deviation between the possible weight and the basic weights to further improve the reliability of the assessment results [34]. The calculation steps are as follows.

The first step is to construct a vector set of the possible weights:

$$
\boldsymbol{U}=\sum_{K=1}^{L} \alpha_{k} \boldsymbol{u}_{k}^{T} \quad \alpha_{k}>0
$$

where $U$ is one possible weight vector in the possible weight vector set and $\alpha_{k}$ is the weight coefficient. In this paper, two kinds of weights are obtained by the game theory coupling entropy method and clustering weight method, so $\mathrm{n}=2$.

The second step is to check the consistency.

The index weights obtained by different weighting methods may vary a lot and even conflict with each other, so weight consistency needs to be checked before combining weights. If the weights fail to pass the consistency check [35], they need to be adjusted to meet the requirements. The following can be used to check the consistency when $\mathrm{n}=2$ :

$$
d\left[w^{(1)} w^{(2)}\right]=\left\{\frac{1}{n} \sum_{i=1}^{n}\left[w^{(1)}-w^{(2)}\right]^{2}\right\}^{1 / 2}
$$

where $w^{(1)}$ and $w^{(2)}$ are the two groups of weights who taking part in the game and $n$ is the index vector number of each

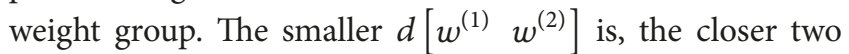

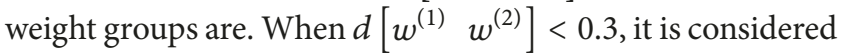
to have passed the consistency check and the weights can be combined.

The third step is to find the most satisfying weight vector.

Find the most satisfying $W^{*}$ in all possible vector sets; that is, find the most satisfying weight coefficient $a_{k}$ to minimize the deviation between $W$ and each $W_{k}$ :

$$
\min =\left\|\sum_{j=1}^{n} \alpha_{j} W_{j}^{T}-W_{i}\right\|_{2} \quad(i=1,2, \ldots, n)
$$

According to the differential characteristics of the matrix, the most optimized conditions of the first derivative in (24) are as follows:

$$
\begin{gathered}
{\left[\begin{array}{cccc}
w_{1} \bullet w_{1}^{T} & w_{1} \cdot w_{2}^{T} & \ldots & w_{1} \bullet w_{L}^{T} \\
w_{2} \bullet w_{1}^{T} & w_{2} \cdot w_{2}^{T} & \ldots & w_{2} \cdot w_{L}^{T} \\
\ldots & \ldots & \ldots & \ldots \\
w_{L} \bullet w_{1}^{T} & w_{L} \cdot w_{2}^{T} & \ldots & w_{L} \cdot w_{L}^{T}
\end{array}\right]\left[\begin{array}{c}
\alpha_{1} \\
\alpha_{2} \\
\ldots \\
\alpha_{L}
\end{array}\right]} \\
=\left[\begin{array}{c}
w_{1} \cdot w_{1}^{T} \\
w_{2} \cdot w_{2}^{T} \\
\ldots \\
w_{L} \bullet w_{L}^{T}
\end{array}\right]
\end{gathered}
$$

The fourth step is to normalize the sets of combination coefficients.

The sets of combination coefficients $\alpha_{1}, \alpha_{2}, \ldots, \alpha_{n}$ can be calculated by (26) and then use (27) to normalize them.

$$
a_{k}^{*}=\frac{a_{k}}{\sum_{k=1}^{L} a_{k}}
$$

The fifth step is to calculate the comprehensive weight

$$
W^{*}=\sum_{k=1}^{L} a_{k}^{*} W_{k}^{T}
$$

\section{Model Instance Verification}

4.1. Health Status Grading. Combining the maintenance measures and processing requirements, the structural condition of ancient timber buildings can be classified into five grades [36-40]: I favorable, II ordinary, III poor, IV inferior, and $\mathrm{V}$ dangerous. The corresponding relationships among structural damage classification, maintenance measures, and processing requirements of ancient timber building structural condition are shown in Table 1.

4.2. Construct the Evaluation Index System and Index Pretreatment. Based on related research [4, 8, 16, 26, 27, 37, 38, 41, 42], we selected soil and foundation (including bearing capacity of foundation soil, subbase deformation, foundation damage, column, and foundation connection), and superstructure (including bearing capacity of member, connection construction, member deformation, crack slope, crack depth, and decayed/insect-attacked) as evaluation factors to construct the structural condition evaluation index system for ancient timber buildings and the evaluation criteria for these factors, as shown in Tables 2 and 3.

4.3. Data Acquisition and Analysis. A building built in the Republican Period in Sino-Ocean Taikoo Li, Chengdu (hereinafter referred to as a building in Chengdu, whose external facade is shown in Figure 1). The timber of the building is pine wood (including individual cedar wood), the retaining wall is built with grey bricks, the roof of the house is made of Chinese-style tiles laid with sand mortar, and there are 
TABLE 1: Corresponding relationships among health status, damage classifications, and maintenance measures.

\begin{tabular}{|c|c|c|c|c|}
\hline Grades & Health status & $\begin{array}{c}\text { Damage } \\
\text { classifications }\end{array}$ & $\begin{array}{c}\text { Maintenance } \\
\text { measures }\end{array}$ & Processing requirements \\
\hline I & Favorable & Basically intact & $\begin{array}{c}\text { Routine } \\
\text { maintenance }\end{array}$ & $\begin{array}{l}\text { Measures should be taken } \\
\text { to a few general members. }\end{array}$ \\
\hline II & Ordinary & Slight damage & $\begin{array}{l}\text { Minor } \\
\text { maintenance }\end{array}$ & $\begin{array}{l}\text { Measures should be taken } \\
\text { to a few members. }\end{array}$ \\
\hline III & Poor & Medium damage & $\begin{array}{l}\text { Medium } \\
\text { maintenance }\end{array}$ & $\begin{array}{l}\text { Measures should be taken } \\
\text { to most of the members, } \\
\text { and measures must be } \\
\text { taken timely to the } \\
\text { individual members. }\end{array}$ \\
\hline IV & Inferior & Heavy damage & $\begin{array}{c}\text { Major } \\
\text { maintenance }\end{array}$ & $\begin{array}{l}\text { Measures must be taken } \\
\text { timely to some members. }\end{array}$ \\
\hline $\mathrm{V}$ & Dangerous & Close to collapse & $\begin{array}{c}\text { Rescue } \\
\text { maintenance }\end{array}$ & $\begin{array}{l}\text { Measures must be taken } \\
\text { immediately. }\end{array}$ \\
\hline
\end{tabular}

TABLE 2: Structural condition evaluation index system for ancient timber buildings.

\begin{tabular}{|c|c|c|c|}
\hline Target & Criteria & Index & Index evaluation \\
\hline \multirow{4}{*}{ Structure condition of ancient timber buildings } & \multirow{4}{*}{ Soil and foundation } & Bearing capacity of foundation soil $c_{1}$ & $\left(P_{d} / f_{s c}\right)-0.1$ \\
\hline & & Subbase deformation $c_{2}$ & $h_{\triangle} / l_{0}$ \\
\hline & & Foundation damage $c_{3}$ & $V / V_{0}$ \\
\hline & & Column and foundation connection $c_{4}$ & $S_{\rho} / S_{b 0}$ \\
\hline \multirow{6}{*}{ Structure condition of ancient timber buildings } & \multirow{6}{*}{ Superstructure } & Bearing capacity of member $c_{5}$ & $\left(R / \Upsilon_{0} S\right)-0.1$ \\
\hline & & Connection construction $c_{6}$ & CC \\
\hline & & Member deformation $c_{7}$ & $100 \omega / l_{c}$ \\
\hline & & Crack slope $c_{8}$ & $k$ \\
\hline & & Crack depth $c_{9}$ & $t / b$ \\
\hline & & Decayed/insect-attacked $c_{10}$ & $S_{\alpha} / S_{u 0}$ \\
\hline
\end{tabular}

Note: $P_{d}$ is the average compressive stress value of the foundation bed, $f_{s c}$ is the characteristic value of the foundation soil bearing capacity. $h_{\triangle}$ is the maximum differential settlement of plinths $(\mathrm{mm}), l_{0}$ is the center distance between adjacent plinths $(\mathrm{mm})$. V is the total volume of the damaged (corrosive, puffing, loose, spalling) area of foundation, $V_{0}$ is the total volume of the foundation before damage, $S_{\rho}$ is the actual bearing area between the bottom of the column base and foundation, $S_{b 0}$ is the original sectional area of the column at the bottom; R is the resistance of structural members, $\Upsilon_{0}$ is the important structural coefficient, $S$ is the effect of actions. CC is the condition of the node construction, when the mode of the node and connection is correct, and there is no deficiency, CC takes $0 \sim 0.10$; when the mode of the node and connection is correct, there is only local deficiency on the surface, CC takes $0.10 \sim 0.15$; when the mode of the node and connection is improper, there is obvious deficiency in the construction, and has resulted in slight looseness and deformation of the connection, CC takes $0.15 \sim 0.20$; when there is obvious looseness, deformation, slippage, and crack at the surface of shear, $C C>0.25 . \omega$ is the lateral bending arch rise of the column, or the maximum deflection of the main beam, truss, or roof truss; $l_{c}$ is the unbraced length of the column, or the calculated span (mm) of the truss, roof truss, or main beam. $\mathrm{k}$ is the sine value of the angle between the cracks and the timber parallel to the grain; $t$ is the depth of the crack, $b$ is the section area of the members along the crack depth direction; $S_{\alpha}$ is the total area of decay, aging deterioration, and insect-attack, $S_{u 0}$ is the overall section area of the members.

TABLE 3: Assessment criteria of the evaluation factors.

\begin{tabular}{|c|c|c|c|c|c|c|c|c|c|c|}
\hline $\begin{array}{l}\text { Evaluation } \\
\text { factor }\end{array}$ & $c_{1}$ & $c_{2}$ & $c_{3}$ & $c_{4}$ & $c_{5}$ & $c_{6}$ & $c_{7}$ & $c_{8}$ & $c_{9}$ & $c_{10}$ \\
\hline $\begin{array}{l}\text { Attribute } \\
\text { category }\end{array}$ & $\begin{array}{l}\text { Positive } \\
\text { index }\end{array}$ & $\begin{array}{l}\text { Negative } \\
\text { index }\end{array}$ & $\begin{array}{c}\text { Negative } \\
\text { index }\end{array}$ & $\begin{array}{l}\text { Negative } \\
\text { index }\end{array}$ & $\begin{array}{l}\text { Positive } \\
\text { index }\end{array}$ & $\begin{array}{l}\text { Negative } \\
\text { index }\end{array}$ & $\begin{array}{l}\text { Negative } \\
\text { index }\end{array}$ & $\begin{array}{l}\text { Negative } \\
\text { index }\end{array}$ & $\begin{array}{l}\text { Negative } \\
\text { index }\end{array}$ & $\begin{array}{l}\text { Negative } \\
\text { index }\end{array}$ \\
\hline I & $\geq 0.90$ & $0 \sim 0.14$ & $0 \sim 0.05$ & $0 \sim 0.05$ & $\geq 0.90$ & $0 \sim 0.10$ & $0 \sim 0.38$ & $0 \sim 0.01$ & $0 \sim 0.10$ & $0 \sim 0.04$ \\
\hline II & $0.9 \sim 0.85$ & $0.14 \sim 0.28$ & $0.05 \sim 0.1$ & $\begin{array}{c}0.05 \sim \\
0.27\end{array}$ & $0.9 \sim 0.85$ & $0.10 \sim 0.15$ & $\begin{array}{c}0.38 \sim \\
0.43\end{array}$ & $0.01 \sim 0.05$ & $0.10 \sim 0.17$ & $\begin{array}{c}0.04 \sim \\
0.06\end{array}$ \\
\hline III & $\begin{array}{c}0.85 \sim \\
0.80\end{array}$ & $0.28 \sim 0.53$ & $0.1 \sim 0.20$ & $\begin{array}{c}0.27 \sim \\
0.46\end{array}$ & $\begin{array}{c}0.85 \sim \\
0.80\end{array}$ & $0.15 \sim 0.20$ & $0.43 \sim 0.55$ & $0.05 \sim 0.10$ & $0.17 \sim 0.20$ & $0.06 \sim 0.10$ \\
\hline IV & $\begin{array}{c}0.80 \sim \\
0.75\end{array}$ & $0.53 \sim 0.87$ & $\begin{array}{c}0.20 \sim \\
0.30\end{array}$ & $\begin{array}{c}0.49 \sim \\
0.70\end{array}$ & $\begin{array}{c}0.80 \sim \\
0.75\end{array}$ & $\begin{array}{c}0.20 \sim \\
0.25\end{array}$ & $0.55 \sim 0.65$ & $0.10 \sim 0.15$ & $\begin{array}{c}0.20 \sim \\
0.25\end{array}$ & $0.10 \sim 0.13$ \\
\hline V & $<0.75$ & $>0.87$ & $>0.30$ & $>0.70$ & $<0.75$ & $>0.25$ & $>0.65$ & $>0.15$ & $>0.25$ & $>0.13$ \\
\hline
\end{tabular}


TABLE 4: Field detection value of parameters of each evaluation index.

\begin{tabular}{lcr}
\hline Index & Parameter & Index value \\
\hline$c_{1}$ & $/$ & 0.96 \\
$c_{2}$ & $/$ & 0.06 \\
$c_{3}$ & $/$ & 0.03 \\
$c_{4}$ & $\omega=13 \mathrm{~mm}, l_{c}=3100 \mathrm{~mm}$ & 0.03 \\
$c_{6}$ & $k=0.17$ & 0.18 \\
$c_{7}$ & $t=54 \mathrm{~mm}, b=200 \mathrm{~mm}$ & $k=0.17$ \\
$c_{8}$ & $S_{c}=32.71 \mathrm{~cm}^{2}, S_{u 0}=490.63 \mathrm{~cm}^{2}$ & $t / b=0.27$ \\
$c_{9}$ & $S_{\alpha} / S_{u 0}=0.07$ \\
$c_{10}$ & & $k$
\end{tabular}

Note. The foundation soil of this building is in good condition with no obvious settlement; we do not have to worry about the bearing capacity of foundation soil. The foundation of this building's wood column is made of red sandstone, there are no obvious settlement at the column base and no obvious slab staggering between the column and foundation, and the foundation is in good condition; we do not have to worry about the bearing capacity of it. The mode of the node and connection of this building is correct, but slight looseness appears at part of the beam-column nodes.

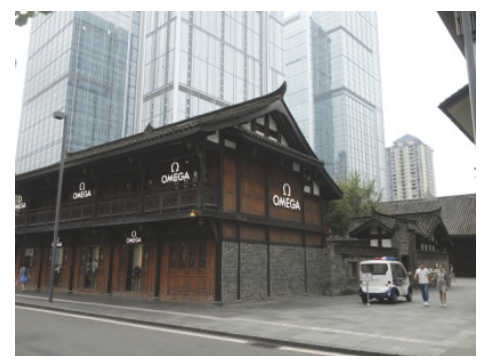

FIgURe 1: Courtyards built in the Republican Period in Chengdu.

overhanging eaves both at the front and back of the building. In September 2014, it was listed in the second batch of historic buildings on the protection list in Chengdu.

4.3.1. Field Detection. By use of related equipment and instruments (such as the Electronic Total Station PENTAX R$322 \mathrm{NX}$, vernier caliper, and plumb bob), the concrete parameter of 9 indexes including bearing capacity of foundation soil $c_{1}$, subbase deformation $c_{2}$, foundation damage $c_{3}$, column and foundation connection $c_{4}$, connection construction $c_{6}$, member deformation $c_{7}$, crack slope $c_{8}$, crack depth $c_{9}$, and decayed/insect-attacked $c_{10}$ were detected, and the related concrete data are shown in Table 4.

4.3.2. Finite Element Calculation. After the field measurements of the beam-column arrangement and member section sizes, the SAP 2000 finite element model for a building in Chengdu was established (as shown in Figure 2). Thereinto, the BEAM element was used to simulate the columns and beams of this structure, while the PLATE element was used to simulate the floor slab and roof slab. In order to simulate the structural performance more accurately, part of the bending stiffness of the beam was released at the joint of the column and beam, so as to realize the characteristic of semirigid connection and semihinged connection; the boundary condition of the bottom of each column was hinge joint, so as to stimulate the real boundary condition of the actual structure. As for settings of the timber structural materials, the anisotropy parameters were adopted to accurately stimulate the diversity of the timber parallel to grain and perpendicular to grain. Wind loads were applied to the structure by means of rigid plates. The specific values of the other parameters are shown in Table 5. According to the calculation of the finite element model SAP 2000, the ratios of the resistance to the effect of action of the compression-flexure, bending, and shearing capacity of this building's members (wood column, wood brace, wood beam, purlin, and rafter) were all over 1.05, and then the index value of the bearing capacity of the members $c_{5}$ was 0.95 .

Above all, the assessment criteria of the evaluation factors (Table 3) and index value (Table 4 and index value $c_{5}$ ) of the comprehensive evaluation factors of the structural condition assessment of a building in Chengdu were normalized according to (14) and (15), as shown in Tables 6 and 7, respectively.

\subsection{Health Assessment}

4.4.1. Construct a Structural Condition Fuzzy Matter-Element of the Ancient Timber Buildings. $k_{0}$ and $t$ can be calculated according to (6) and Table 6, so the normalized fuzzy matterelement of the structural condition of a building in Chengdu can be obtained by plugging Table 7 into (2) and (5):

$$
R=\left[\begin{array}{cccccc} 
& \text { I } & \text { II } & \text { III } & \text { IV } & \text { V } \\
c_{1} & 0.9727 & 0.7792 & 0.7792 & 0.7792 & 0.5752 \\
c_{2} & 0.9860 & 0.9860 & 0.8291 & 0.7481 & 0.9959 \\
c_{3} & 0.9727 & 0.9727 & 0.8950 & 0.8950 & 0.5603 \\
c_{4} & 0.9727 & 0.6931 & 0.6931 & 0.7022 & 0.6418 \\
c_{5} & 1.0000 & 0.5000 & 0.5000 & 0.5000 & 0.5942 \\
c_{6} & 0.0092 & 0.0000 & 0.0000 & 0.0000 & 0.8291 \\
c_{7} & 0.3622 & 0.0000 & 0.0000 & 0.0000 & 0.2571 \\
c_{8} & 0.0000 & 0.0000 & 0.0000 & 0.0000 & 0.7792 \\
c_{9} & 0.0010 & 0.0000 & 0.0000 & 0.0000 & 0.9742 \\
c_{10} & 0.0131 & 0.0000 & 0.0131 & 0.0001 & 0.6139
\end{array}\right]
$$


TABLE 5: The value of each parameter in finite element model.

\begin{tabular}{|c|c|}
\hline Parameter & Value \\
\hline Diameter of short columns ( $\mathrm{mm})$ & A 200 \\
\hline Diameter of other wood columns (mm) & $\mathrm{A} 240 \sim \mathrm{A} 250$ \\
\hline $\begin{array}{l}\text { Sectional dimension of wood brace } \\
\text { (height } \times \text { thickness, } \mathrm{mm} \text { ) }\end{array}$ & $\begin{array}{l}200 \times 80 \\
230 \times 80 \\
250 \times 80\end{array}$ \\
\hline Diameter of wood purlin (mm) & $\mathrm{A} 160, \mathrm{~A} 180$ \\
\hline $\begin{array}{l}\text { Sectional dimension of wood rafter } \\
\text { (width } \times \text { thickness, } \mathrm{mm} \text { ) }\end{array}$ & $90 \times 60$ \\
\hline Dead load standard values of pitched roof & $2.1 \mathrm{kN} / \mathrm{m}^{2}$ \\
\hline Live load standard values of pitched roof & $0.5 \mathrm{kN} / \mathrm{m}^{2}$ \\
\hline The ground roughness & Category D \\
\hline The value of basic wind pressure & $0.3 \mathrm{kN} / \mathrm{m}^{2}$ \\
\hline Strength grade of timber & $44 \mathrm{~N} / \mathrm{mm}^{2}$ \\
\hline The bending design strength reduction coefficient of old timber & 0.9 \\
\hline Shear design strength parallel to grain reduction coefficient of old timber & 0.9 \\
\hline Elastic modulus reduction coefficient of old timber & 0.9 \\
\hline $\begin{array}{l}\text { Bearing design strength perpendicular to grain reduction coefficient of old } \\
\text { timber }\end{array}$ & 0.9 \\
\hline $\begin{array}{l}\text { Compressive design strength parallel to grain adjustment coefficient of old } \\
\text { timber }\end{array}$ & 0.95 \\
\hline Material reduction coefficient of new timber & 1.0 \\
\hline
\end{tabular}

Note. The beam-column nodes were calculated as the hinged connection (the beam of the overhanging support was calculated as the fixed end); the effect of the member crack is not taken into account in the checking calculation. The material reduction coefficient of timber was valued according to [26, 27], while the load was valued according to [28].

TABLE 6: Normalized assessment criteria of the evaluation factors.

\begin{tabular}{lcccc}
\hline Evaluation factors & I & II & III & IV \\
\hline$c_{1}$ & $0.00 \sim 0.10$ & $0.10 \sim 0.15$ & $0.15 \sim 0.20$ & $0.20 \sim 0.25$ \\
$c_{2}$ & $0.00 \sim 0.14$ & $0.14 \sim 0.28$ & $0.28 \sim 0.53$ & $0.53 \sim 0.87$ \\
$c_{3}$ & $0.00 \sim 0.05$ & $0.05 \sim 0.10$ & $0.10 \sim 0.20$ & $0.20 \sim 0.30$ \\
$c_{4}$ & $0.00 \sim 0.05$ & $0.05 \sim 0.27$ & $0.27 \sim 0.49$ & $0.49 \sim 0.70$ \\
$c_{5}$ & $0.00 \sim 0.10$ & $0.10 \sim 0.15$ & $0.15 \sim 0.20$ & $0.20 \sim 0.25$ \\
$c_{6}$ & $0.00 \sim 0.10$ & $0.10 \sim 0.15$ & $0.15 \sim 0.20$ & $0.20 \sim 0.25$ \\
$c_{7}$ & $0.00 \sim 0.38$ & $0.38 \sim 0.43$ & $0.43 \sim 0.55$ & $0.55 \sim 0.65$ \\
$c_{8}$ & $0.00 \sim 0.01$ & $0.01 \sim 0.05$ & $0.05 \sim 0.10$ & $0.10 \sim 0.15$ \\
$c_{9}$ & $0.00 \sim 0.13$ & $0.13 \sim 0.17$ & $0.17 \sim 0.25$ & $0.25 \sim 0.33$ \\
$c_{10}$ & $0.00 \sim 0.04$ & $0.04 \sim 0.06$ & $0.06 \sim 0.10$ & $0.30 \sim 1.00$ \\
\end{tabular}

TABLE 7: Normalized index value of the comprehensive evaluation factors of the structural condition assessment of a building in Chengdu.

\begin{tabular}{lcccccccccc}
\hline Evaluation factors & $c_{1}$ & $c_{2}$ & $c_{3}$ & $c_{4}$ & $c_{5}$ & $c_{6}$ & $c_{7}$ & $c_{8}$ & $c_{9}$ & $c_{10}$ \\
\hline Index value & 0.04 & 0.06 & 0.03 & 0.03 & 0.05 & 0.18 & 0.42 & 0.17 & 0.27 & 0.07 \\
\hline
\end{tabular}

4.4.2. Weights Calculation. According to (13)-(28), Table 4 and the index value $c_{5}$, as well as Table 6 , can be used to calculate the weight of $w_{1}$ (entropy weight method), weight $w_{2}$ (clustering weight method), and the comprehensive weight $w^{*}$ (game theory) of the structural condition assessment of a building in Chengdu, as shown in Table 8.
4.4.3. Calculation of Membership Degree and Asymmetrical Proximity. The structural condition assessment membership degree of the building in Chengdu can be calculated according to the data in (7) and (29) and Table 8, and the membership degree $B$ can be normalized to obtain $B^{(i)}, i=$ $1,2, \cdots, 5$; then the asymmetric proximity degree $N\left(\boldsymbol{B}_{i}^{j}, \boldsymbol{D}_{j}\right)$ 


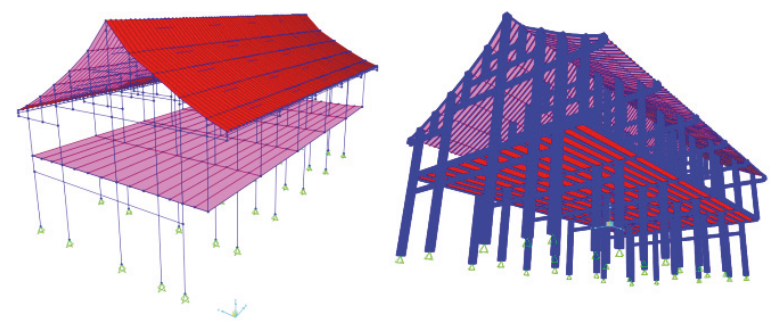

Figure 2: The SAP 2000 finite element model of a building in Chengdu.

TABLE 8: Weight $w_{1}, w_{2}$ and comprehensive weight $w^{*}$.

\begin{tabular}{|c|c|c|c|c|c|c|c|c|c|c|}
\hline Evaluation index & $c_{1}$ & $c_{2}$ & $c_{3}$ & $c_{4}$ & $c_{5}$ & $c_{6}$ & $c_{7}$ & $c_{8}$ & $c_{9}$ & $c_{10}$ \\
\hline Entropy weight $w_{1}$ & 0.0996 & 0.0923 & 0.1026 & 0.0947 & 0.0996 & 0.0996 & 0.0877 & 0.1150 & 0.0965 & 0.1124 \\
\hline Clustering weight $w_{2}$ & 0.0233 & 0.0321 & 0.0250 & 0.0273 & 0.0291 & 0.1049 & 0.1513 & 0.3939 & 0.1409 & 0.0722 \\
\hline Consistency test & \multicolumn{10}{|c|}{$d\left[\begin{array}{ll}w_{1} & w_{1}\end{array}\right]=0.2350<0.3$} \\
\hline Comprehensive weight $w^{*}$ & 0.0183 & 0.0283 & 0.0199 & 0.0229 & 0.0246 & 0.1068 & 0.1580 & 0.4195 & 0.1462 & 0.0705 \\
\hline
\end{tabular}

TABLE 9: Membership degree $B$ and normalized $\boldsymbol{B}^{(i)}$.

\begin{tabular}{lcccrr}
\hline Evaluation factors & I & II & III & IV & V \\
\hline$B$ & 0.1713 & 0.0897 & 0.0847 & 0.0817 & 0.0897 \\
$B^{(1)}$ & 0.7209 & 0.0817 & 0.0847 & 0.1713 & 0.1713 \\
$B^{(2)}$ & 0.7209 & 0.0817 & 0.0847 & 0.0897 & 0.0897 \\
$B^{(3)}$ & 0.7209 & 0.1713 & 0.0817 & 0.0847 & 0.0847 \\
$B^{(4)}$ & 0.0847 & 0.7209 & 0.7209 & 0.0817 & 0.0817 \\
$B^{(5)}$ & 0.1713 & 0.0897 & 0.0847 & 0.8926 & 0.7209 \\
$N\left(\boldsymbol{B}^{j}, \boldsymbol{D}_{j}\right)$ & 0.7762 & 0.7600 & 0.695 & 0.7936 \\
\hline
\end{tabular}

of the structural condition assessment of the building in Chengdu can be obtained by plugging $B^{(i)}$ into (10), as shown in Table 9.

4.4.4. Results and Discussion. $\max _{1 \leq j \leq m} N\left(\boldsymbol{B}^{\boldsymbol{j}}, \boldsymbol{D}_{j}\right)=N\left(\boldsymbol{B}^{4}\right.$, $D_{4}$ ) can be obtained according to (12), which shows that the fuzzy matter-element assessment result of the structural condition of the building in Chengdu, based on asymmetric proximity, is inferior and measures must be taken timely to some members.

The actual status of the building in Chengdu is as shown in Figure 3. Desiccation cracks exist parallel to grain and diagonal cracks appear at most of the timber columns; the crack slope is large and the depth of cracks is close to $1 / 3$ of the column diameter. Part of the timber columns with desiccation cracks was reinforced with an iron hoop a few years ago, but the reinforced columns cracked again, slight looseness appears at the nodes of part of the timber columns, and part of the timber columns show evidence of insect attack. Desiccation cracks appear widespread at the timber purlins; the cracks are mainly diagonal cracks and continuous longitudinal cracks, the maximum slope of the diagonal cracks exceeds $15 \%$, and the maximum depth of cracks exceeds $1 / 4$ of the diameter of individual purlin.

According to the stipulations in $[37,42]$, when the crack slope of the tension member and tension-flexure member exceeds $10 \%$, or the crack slope of the flexural member and eccentric compression member exceeds $15 \%$, or the crack slope of the compression member exceeds $20 \%$, there are serious safety risks in the structure and measures must be taken immediately. The crack slope of the compression member of the building in Chengdu is 0.17 , less than the limit value 0.20 that measures must be taken immediately required in $[37,42]$. According to the stipulations in references [27, 42], when the crack depth of the wood column reaches $1 / 3$ of the column diameter, or the crack depth of the beam-brace reaches $1 / 4$ of the beam-brace diameter, there are serious safety risks in the structure and measures must be taken immediately. The crack depth of the wood column of the building in Chengdu is 0.27 of the column diameter; it is less than $1 / 3$; and the crack depth of the beam-brace is also less than $1 / 4$ of the beam-brace diameter; that is, less than the limit value that measures must be taken immediately required in $[27,42]$. Therefore, according to the safety assessment limit requirements of the related indexes of timber structure in $[27,37,42]$, the structure safety of the building in Chengdu belongs to the grade "there are serious safety risks in the structure, measures must be taken timely to some members". As shown in Table 9, by using of the fuzzy matter-element method improved by asymmetric proximity, the health status of the building in Chengdu is "inferior" and "measures must be taken timely to some members." It shows that the 


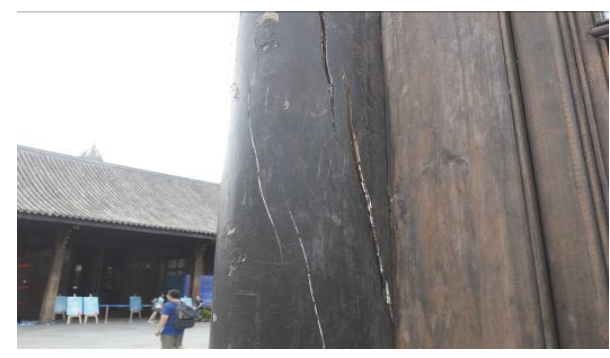

(a) Diagonal cracks appear at the timber columns

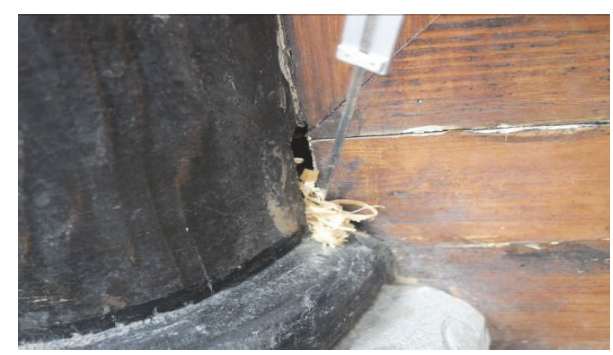

(b) The base of the timber columns have been attacked by insects

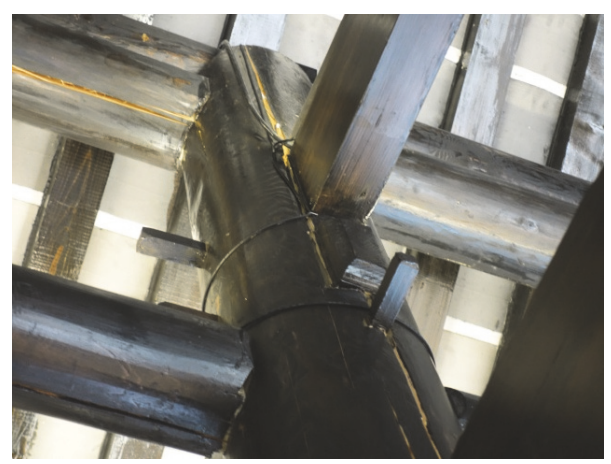

(c) Serious desiccation cracks appear at the beamcolumn nodes of the wood column, and temporary reinforcement measures have been taken

Figure 3: Current status of the building in Chengdu.

assessment results derived from the method in this paper are not only consistent with the results from references [27, $37,42]$ but also conform to the objective reality, as well as accurate and credible.

As shown in Table 9, by use of the traditional matterelement method, the health status of the building in Chengdu is "dangerous" and "measures must be taken immediately." But the result of the fuzzy matter-element method improved by asymmetric proximity is that the health status of the building is "inferior" and "measures must be taken timely to some members." It shows that adopting the fuzzy matterelement model improved by asymmetric proximity can avoid failure judgment.

\section{Conclusions}

In this paper, 10 individual indexes including bearing capacity of foundation soil, subbase deformation, foundation damage, column and foundation connection, bearing capacity of members, connection construction, member deformation, crack slope, crack depth, and decay/insect attack were selected as evaluation factors to establish the structural condition assessment model of ancient timber buildings. The model was put into practice by analyzing a building in Chengdu, and the results show the following:

(1) The structural condition assessment model of ancient timber buildings is constructed with fuzzy matter elements based on the principle of asymmetric proximity; this model can solve the failure problem of maximum membership principle and is suitable for a multilayer and multiobjective assessment system.

(2) Adopting the game theory method to combine the weights determined by the entropy weight method and clustering method can effectively avoid the subjectivity and randomness of allocating the weight of indexes and ensure reliability of the assessment results.

(3) The calculation example shows that the assessment results are consistent with objective reality. Applying the fuzzy matter-element model improved by asymptotic proximity to analyze the structural condition of ancient timber buildings is simple, practical, and feasible; it can provide a decision-making basis for scientific protection, maintenance, and reinforcement of ancient timber buildings.

\section{Data Availability}

The data used to support the findings of this study are included within the article.

\section{Conflicts of Interest}

The authors declare that they have no conflicts of interest.

\section{Acknowledgments}

The work was supported by "the $12^{\text {th }}$ Five-Year Plan" National Science-technology Support Plan Projects (no. 2013BAK01B03) and Technical Research on Protection and 
Sustainable Utilization for Excellent Historical Buildings in Sichuan Province (Scheme no. HXKX2014/014).

\section{References}

[1] Q. Zhou, W. M. Yan, Z. B. Li et al., "Study on strengthening methods of timber structures of ancient buildings," Earthquake Resistant Engineering and Retrofitting, vol. 31, no. 1, pp. 84-90, 2009.

[2] S. Shen, W. L. Jiang, and Y. Shan, "Research on health monitoring technology for ancient building based on WSN," China Measurement Test, vol. 43, no. 11, pp. 64-69, 2017.

[3] J. Li, X. Zhang, J. Li, R. Li, M. Qian, and P. Song, "An experimental study of the damage degrees to ancient building timber caused by lightning strikes," Journal of Electrostatics, vol. 90, pp. 23-30, 2017.

[4] Y. G. Wang, J. Y. Su, and X. S. Song, "Experimental study on the influence of side column's settlement in ancient chinese woodenbuildings on the wooden frame," ICCERE 2015, pp. 218-228, 2015.

[5] B. Jaishi, W.-X. Ren, Z.-H. Zong, and P. N. Maskey, "Dynamic and seismic performance of old multi-tiered temples in Nepal," Engineering Structures, vol. 25, no. 14, pp. 1827-1839, 2003.

[6] S. J. Qin and N. Yang, "Strength degradation and service life prediction of timber in ancient Tibetan building," European Journal of Wood and Wood Products, vol. 4, pp. 1-17, 2017.

[7] Y. F. Wu and X. Z. Sun, "The Research of Huizhou Ancient Wood Buildings Fire Prevention and Control Strategy," ICACE 2016, pp. 312-319, 2016.

[8] Q. Zhou, W. M. Yan, and J. B. Ji, "Aseismic constitution problems and strengthening methods of Chinese ancient wooden buildings," Applied Mechanics and Materials, vol. 351-352, pp. 15631567, 2013.

[9] A. Pesci, G. Casula, and E. Boschi, "Laser scanning the Garisenda and Asinelli towers in Bologna (Italy): Detailed deformation patterns of two ancient leaning buildings," Journal of Cultural Heritage, vol. 12, no. 2, pp. 117-127, 2011.

[10] F. H. Wang, X. Y. Huang, and W. M. Wang, "The application of fuzzy mathematic in earthquake damage about ancient buildings," Applied Mechanics and Materials, vol. 501-504, pp. 1513-1519, 2014.

[11] M. Lyu, X. Zhu, and Q. Yang, "Dynamic field monitoring data analysis of an ancient wooden building in seismic and operational environments," Earthquake and Structures, vol. 11, no. 6, pp. 1043-1060, 2016.

[12] W. Zhou, H. D. Guo, and Q. Li, "Fine deformation monitoring of ancient building based on terrestrial laser scanning technologies," IOP Conference Series-Earth and Environmental Science, vol. 17, no. 1, pp. 682-691, 2014.

[13] X. C. Zhang, J. Y. Xue, and H. T. Zhao, "Experimental study on Chinese ancient timber-frame building by shaking table test," Structural Engineering Mechanics, vol. 40, no. 4, pp. 453-469, 2011.

[14] J. Y. Xue, Z. J. Wu, F. L. Zhang, and H. T. Zhao, "Seismic damage evaluation model of Chinese ancient timber buildings," Advances in Structural Engineering, vol. 18, no. 10, pp. 1671-1683, 2015.

[15] N. Yang, P. Li, S. S. Law, and Q. Yang, "Experimental research on mechanical properties of timber in ancient tibetan building," Journal of Materials in Civil Engineering, vol. 24, no. 6, pp. 635643, 2012.
[16] W. D. Tan, L. Zhu, and T. L. Yan, "Under the action of earthquake ancient timber building column small feet slip phenomenon analysis," Applied Mechanics and Materials, vol. 353354, pp. 1930-1933, 2013.

[17] I. A. Naziris, N. D. Lagaros, and K. Papaioannou, "Selection and resource allocation model for upgrading fire safety of historic buildings," Journal of Management in Engineering, vol. 32, no. 4, 2016.

[18] Y. G. Xue, S. C. Li, and D. F. Zhang, "Vibration characteristics in subway operation and environmental responses of ancient buildings," Polish Journal of Environmental Studies, vol. 23, no. 1, pp. 231-241, 2014.

[19] F. Calderón, G. Palazzo, V. Roldan et al., "Changes of dynamic properties in an ancient masonry building due to environmental conditions," in Proceedings of the International Operational Modal Analysis Conference, vol. 112, pp. 313-321, 2015.

[20] L. Fregonese, G. Barbieri, L. Biolzi, M. Bocciarelli, A. Frigeri, and L. Taffurelli, "Surveying and monitoring for vulnerability assessment of an ancient building," Sensors, vol. 13, no. 8, pp. 9747-9773, 2013.

[21] L. Dai, N. Yang, L. Zhang, Q. Yang, and S.-S. Law, "Monitoring crowd load effect on typical ancient Tibetan building," Structural Control and Health Monitoring, vol. 23, no. 7, pp. 998-1014, 2016.

[22] Z.-U. Rehman and A. Khan, "Prediction of GPCRs with Pseudo amino acid composition: Employing composite features and grey incidence degree based classification," Protein and Peptide Letters, vol. 18, no. 9, pp. 872-878, 2011.

[23] H.-Y. Cui, Y. Zhao, Y.-N. Chen et al., "Assessment of phytotoxicity grade during composting based on EEM/PARAFAC combined with projection pursuit regression," Journal of Hazardous Materials, vol. 326, pp. 10-17, 2017.

[24] Q. Zhang, J.-C. Wang, and H.-X. Zhang, "Attribute recognition model and its application of risk assessment for slope stability at tunnel portal," Journal of Vibroengineering, vol. 19, no. 4, pp. 2726-2738, 2017.

[25] J. Jiao, H. Ren, and S. Sun, "Assessment of surface ship environment adaptability in seaways: A fuzzy comprehensive evaluation method," International Journal of Naval Architecture and Ocean Engineering, vol. 8, no. 4, pp. 344-359, 2016.

[26] MOHURD, GB 50005-2003-Code for Design of Timber Structures, China Architecture \& Building Press, 2005.

[27] MOHURD, JGJ 117-1998-Specification for Engineering Examination and Design of Repairing Civil Architecture, China Architecture \& Building Press, 1998.

[28] MOHURD, GB 50009-2012-Load Code for the Design of Building Structures, China Architecture \& Building Press, 2012.

[29] W. Cai, C. Y. Yang, and W. C. Lin, "Extension engineering method," Science Press, pp. 27-35, 1997 (Chinese).

[30] F. Gao, H. H. Lin, and H. W. Deng, "On the construction and application of the groundwater environment health assessment model based on the game theory-fuzzy matter element," Journal of Safety and Environment, vol. 17, no. 4, pp. 1543-1547, 2017.

[31] X. P. Zhang, "The definition of product about fuzzy comprehensive evaluation methods based on closeness," Journal of Shandong University, vol. 39, no. 2, pp. 25-29, 2004.

[32] X. L. Wang, G. X. Wang, Y. X. Wu et al., “Comprehensive assessment of regional water usage efficiency control based on game theory weight and a matter-element model," Water, vol. 9, no. 2, p. 113, 2017. 
[33] J. Hu, L. Z. Xu, and J. S. Zhang, "Modified Grey Clustering Model on Air Quality Assessment," Journal of Fujian Normal University (Natural Science Edition), vol. 28, no. 1, pp. 49-54, 2012.

[34] C. Lai, X. Chen, X. Chen, Z. Wang, X. Wu, and S. Zhao, "A fuzzy comprehensive evaluation model for flood risk based on the combination weight of game theory," Natural Hazards, vol. 77, no. 2, pp. 1243-1259, 2015.

[35] L. L. Zhang, C. G. Lai, X. H. Chen et al., "Decadal variation and evaluation of flood risk based on the combination weight of game theory," Tropical Geography, vol. 38, no. 2, pp. 217-225, 2018.

[36] Y. Pan, L.-J. Li, H.-Q. Wang, and Y.-Y. Yao, "Research on evaluation methods for post-earthquake damage state of ancient wooden buildings," Journal of Hunan University Natural Sciences, vol. 43, no. 1, pp. 132-142, 2016.

[37] MOHURD, GB 50292-2015-Standard for Appraiser of Reliability of Civil Buildings, China Architecture \& Building Press, 2015.

[38] Beijing municipal commission of housing and urban-rural development, Beijing municipal administration of quality and technology supervision, "DB11/637-2015 Standard for structure comprehensive safety appraisal of buildings," UCST, pp. 78-84, 2015.

[39] N. Li, L. Xu, X. D. Guo, Y. H. Wang et al., "A comprehensive method for evaluation of seismic damage in ancient wooden buildings based on probabilistic theory," Sciences of Conservation \& Archaeology, vol. 24, no. 1, pp. 44-48, 2012.

[40] C. H. Duan, X. D. Guo, and Y. Wu, "Repairing and Strengthening of Ancient Wood Structure on the Basis of Damage Characteristics," Earthquake Resistant Engineering and Retrofitting, vol. 2, no. 1, pp. 126-130, 2014.

[41] MOHURD, GB 50007-2011-Code for Design of Building Foundation, China Architecture \& Building Press, 2011.

[42] MOHURD, GB 50165-1992-Technical Code for Maintenance and Strengthening of Ancient Timber Buildings, China Architecture \& Building Press, 1992. 


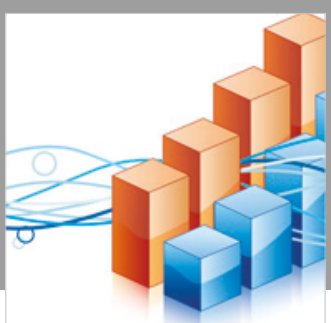

Advances in

Operations Research

\section{-n-m}
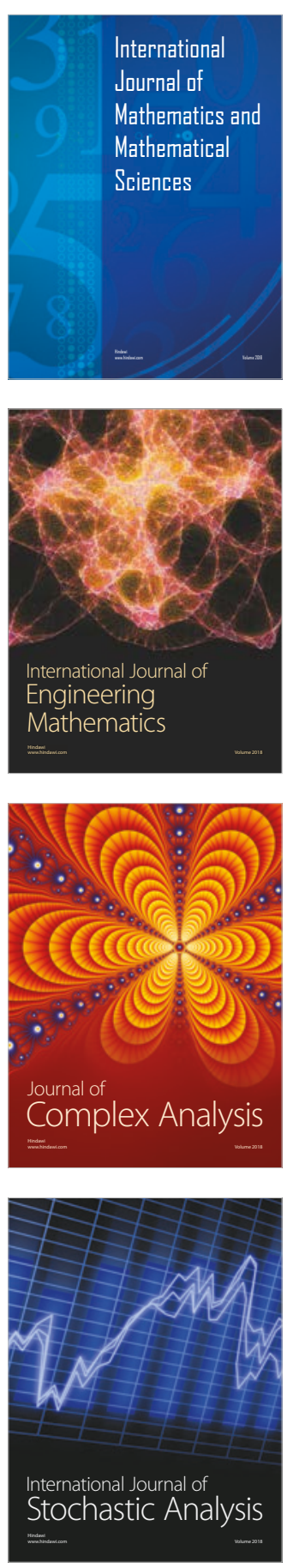
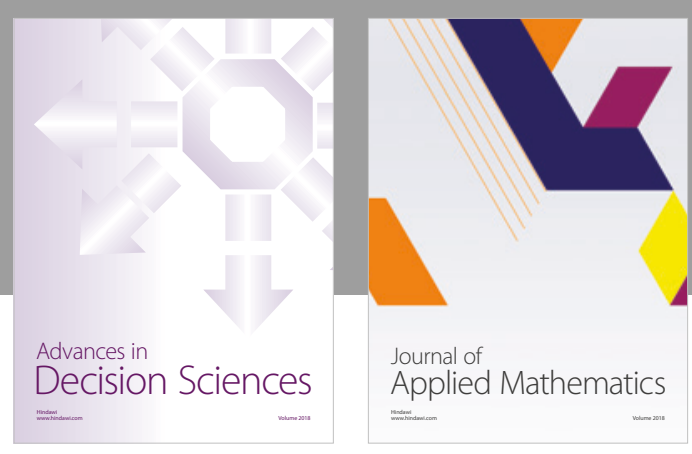

Journal of

Applied Mathematics
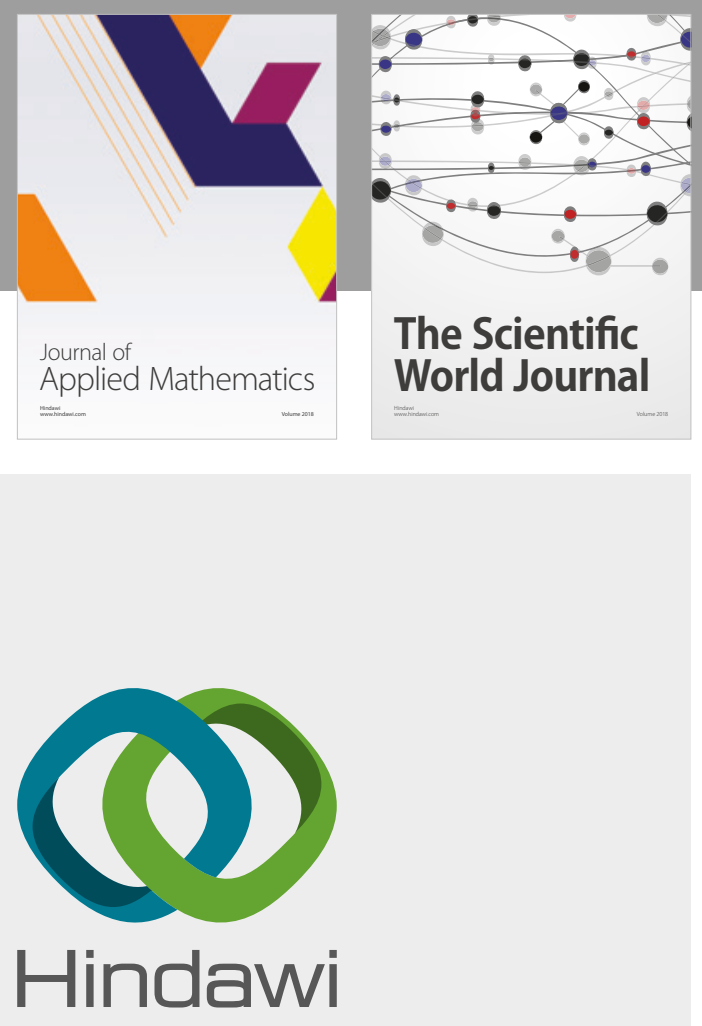

Submit your manuscripts at

www.hindawi.com

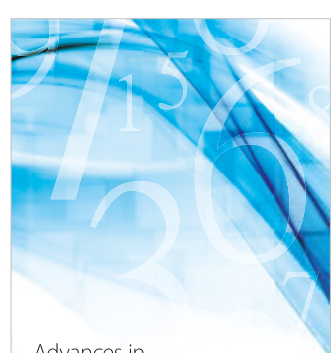

Advances in
Numerical Analysis
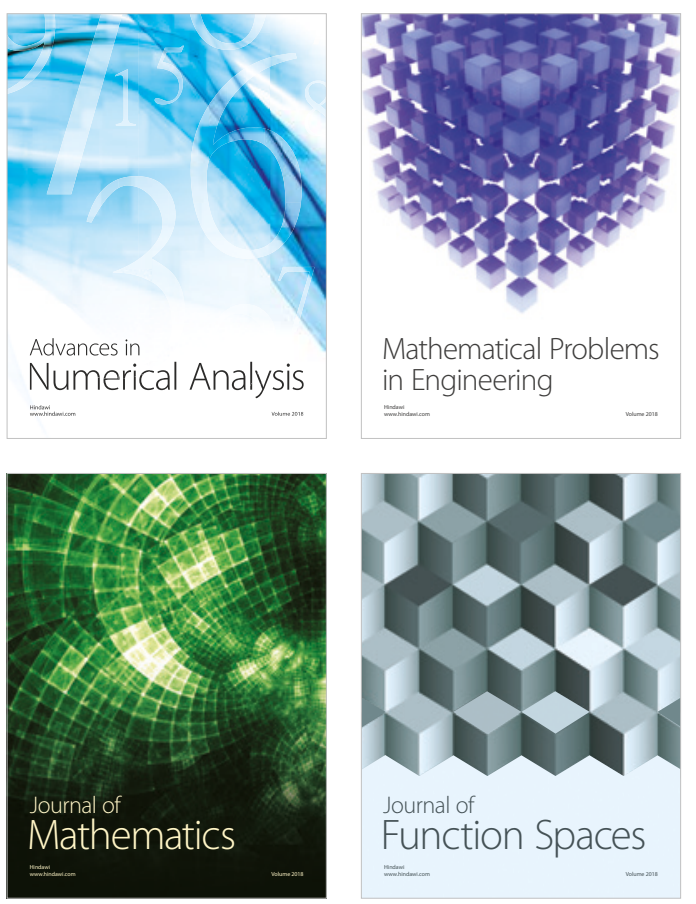

Mathematical Problems in Engineering

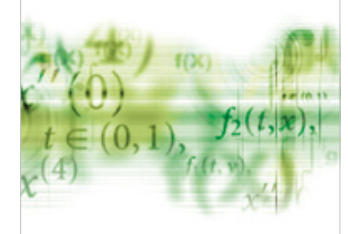

International Journal of

Differential Equations

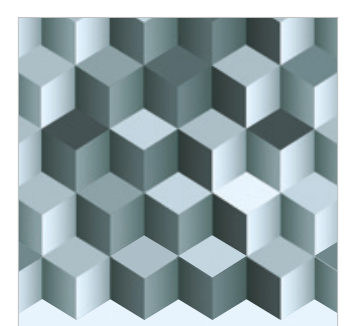

Journal of

Function Spaces
The Scientific

World Journal

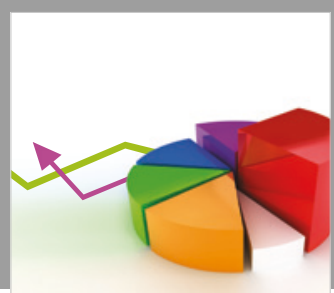

Journal of

Probability and Statistics
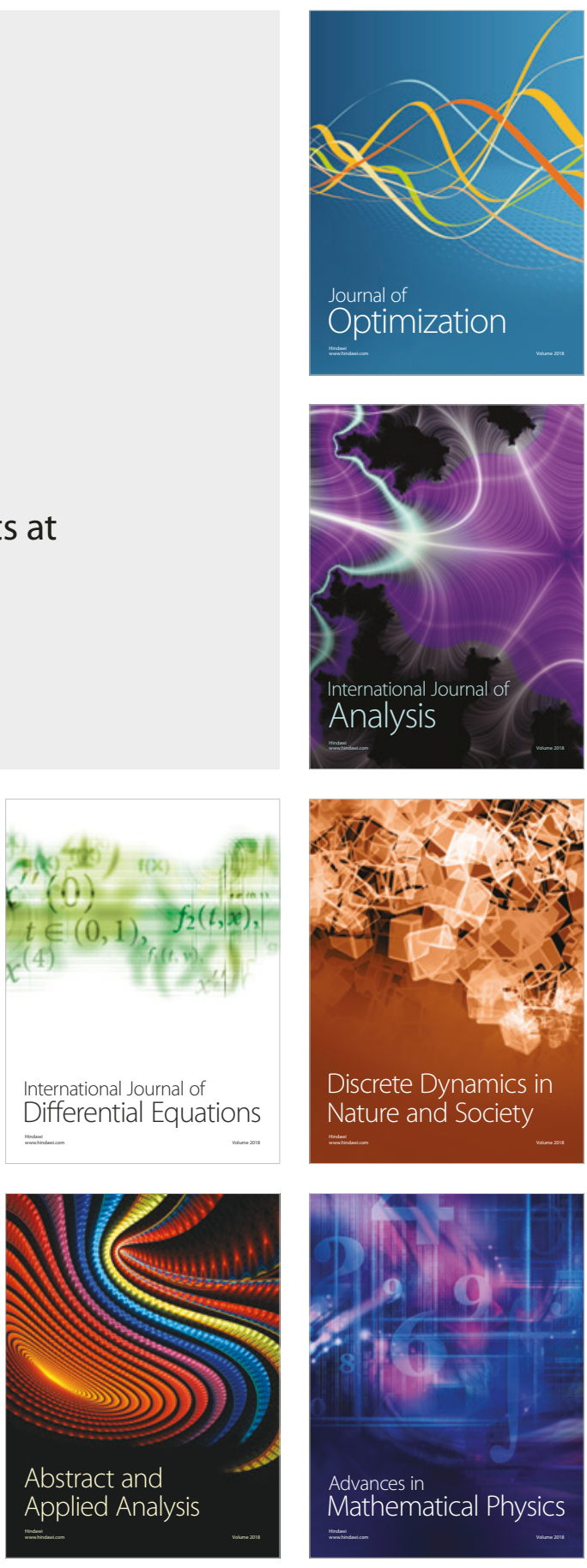